\title{
"PEREMPUAN SEHAT, MASA DEPAN CEMERLANG" PADA HARI PEREMPUAN INTERNASIONAL DI DESA TELAGAWARU LOMBOK BARAT
}

\author{
Siti Mardiyah WD'), Catur Esty Pamungkas'), Cahaya Indah Lestari" ${ }^{1)}$, Indriyani Makmun', \\ Desi Rofita'), Baiq Masdariah"), Evi Diliana'), Dwi Kartika Cahyaningtyas' ${ }^{11}$, \\ A.A Muhammad Nur Kasman"1)
}

\author{
1)Program Studi Kebidanan, Fakultas IImu Kesehatan, Universitas Muhammadiyah Mataram, Mataram, NTB, Indonesia \\ Corresponding author : Siti Mardiyah WD \\ E-mail : sitiwiredarma@gmail.com
}

Diterima 31 Maret 2021, Direvisi 24 April 2021, Disetujui 24 April 2021

\begin{abstract}
ABSTRAK
Pandemi Covid-19 membuat masyarakat lebih banyak mengakses informasi melalui media gadget dari pada ke pelayanan kesehatan, karena selain ketakutan akan terpaparnya covid-19 juga masyarakat dihimbau untuk membatasi mobilisasi termasuk ke layanan kesehatan. Informasi yang salah mengenai bagaimana menjaga kesehatan reproduksi sangat membahayakan masyarakat. Termasuk diataranya adalah mitor-mitos yang berkembangan mengenai kesehatan reproduksi. Tujuan utama memberikan pelayanan kesehatan reproduksi yang komprehensif kepada perempuan termasuk kehidupan seksual dan hak-hak reproduksi perempuan sehingga dapat meningkatkan kemandirian perempuan dalam mengatur fungsi dan proses reproduksinya yang pada akhirnya dapat membawa pada peningkatan kualitas kehidupannya. Pendidikan kesehatan yang diberikan pada 10 orangtua di desa Telagawaru menunjukkan hasil yang signifikan yakni $90 \%$ lbu sudah mengetahui bagaimana pentingnya menjaga kesehatan reproduksi dan cara merawat yang benar.
\end{abstract}

Kata kunci: kesehatan reproduksi; pandemi; covid-19

\begin{abstract}
The Covid-19 pandemic has made people more access to information through gadget media rather than health services, because in addition to the fear of exposure to Covid-19, people are also urged to limit mobilization including to health services. Misinformation about how to maintain reproductive health is very dangerous for society. Included among them are myths about reproductive health. Main Objectives To provide comprehensive reproductive health services to women, including sexual life and women's reproductive rights, so as to increase women's independence in managing their reproductive functions and processes, which in turn can lead to an increase in the quality of their lives. The health education provided to 10 parents in Telagawaru village showed significant results, namely $90 \%$ of mothers already knew how important it was to maintain reproductive health and how to properly care for it.
\end{abstract}

Keywords: reproductive health; pandemi; covid-19

\section{PENDAHULUAN}

Kesehatan reproduksi adalah suatu keadaan sejahtera fisik,mental,dan sosial secara utuh tidak semata-mata bebas dari penyakit atau kecacatan dalam suatu yang berkaitan dengan system reproduksi, fungsi dan prosesnya (Kementrian Kesehatan Republik Indonesia, 2017).

Peraturan Pemerintah Nomor 71 Tahun 2014 Kesehatan Reproduksi yang menjamin setiap orang berhak memperoleh pelayanan kesehatan reproduksi yang bermutu, aman dan dapat dipertanggung jawabkan, dimana peraturan ini juga menjamin kesehatan perempuan dalam usia reproduksi sehingga mampu melahirkan generasi yang sehat, berkualitas yang nantinya berdampak pada penurunan Angka Kematian lbu. Didalam memberikan pelayanan Kesehatan Reproduksi ada dua tujuan yang akan dicapai, yaitu tujuan utama dan tujuan khusus (Pemerintah Republik Indonesia, 2014).

Tujuan Utama Memberikan pelayanan kesehatan reproduksi yang komprehensif kepada perempuan termasuk kehidupan seksual dan hak-hak reproduksi perempuan sehingga dapat meningkatkan kemandirian perempuan dalam mengatur fungsi dan proses reproduksinya yang pada akhirnya dapat membawa pada peningkatan kualitas kehidupannya. Tujuan Khusus yaitu meningkatnya kemandirian wanita dalam memutuskan peran dan fungsi reproduksinya, meningkatnya hak dan tanggung jawab sosial 
wanita dalam menentukan kapan hamil, jumlah dan jarak kehamilan dan meningkatnya peran dan tanggung jawab sosial pria terhadap akibat dari perilaku seksual dan fertilitasnya kepada kesehatan dan kesejahteraan pasangan dan anakanaknya (Prijatni, 2016).

Dukungan yang menunjang wanita untuk membuat keputusan yang berkaitan dengan proses reproduksi, berupa pengadaan informasi dan pelayanan yang dapat memenuhi kebutuhan untuk mencapai kesehatan reproduksi secara optimal. Tujuan diatas ditunjang oleh undang-undang kesehatan No. 23/1992, bab II pasal 3 yang menyatakan: "Penyelenggaraan upaya kesehatan bertujuan untuk meningkatkan derajat kesehatan yang optimal bagi masyarakat", dalam Bab III Pasal 4 "Setiap orang menpunyai hak yang sama dalam memperoleh derajat kesehatan yang optimal.

Konsep Kesehatan Reproduksi menggunakan pendekatan siklus kehidupan perempuan (lifecycle-approach) atau pelayanan kesehatan reproduksi dilakukan sejak dari janin sampai liang kubur (from womb to tomb) atau biasa juga disebut dengan "Continuum of care women cycle“. Kesehatan reproduksi menggunakan pendekatan sepanjang siklus kehidupan perempuan hal ini disebabkan status kesehatan perempuan semasa kanak-kanak dan remaja mempengaruhi kondisi kesehatan saat memasuki masa reproduksi yaitu saat hamil, bersalin, dan masa nifas. Hambatan sosial, budaya, dan ekonomi yang dialami sepanjang hidup perempuan merupakan akar masalah yang mendasar yang menyebabkan buruknya kesehatan perempuan saat hamil, bersalin, dan masa nifas. Tingkat pendidikan, kualitas dan kuantitas makanan, nilai dan sikap, sistem kesehatan yang tersedia dan bisa diakses, situasi ekonomi, serta kualitas hubungan seksualnya mempengaruhi perempuan dalam menjalankan masa reproduksinya (Prijatni, 2016).

Pencegahan dan penanganan infeksi ditujukan pada penyakit dan gangguan yang berdampak pada saluran reproduksi. Baik yang disebabkan penyakit infeksi yang non PMS. Seperti Tuberculosis, Malaria, Filariasis, maupun infeksi yang tergolong penyakit menular seksual, seperti gonorhoea, sifilis, herpes genital, chlamydia, ataupun kondisi infeksi yang mengakibatkan infeksi rongga panggul (pelvic inflammatory diseases/PID) seperti penggunaan alat kontrasepsi dalam rahim (AKDR) yang tidak steril. Semua contoh penyakit tersebut bila tidak mendapatkan penanganan yang baik dapat berakibat seumur hidup pada wanita maupun pria, yaitu misalnya kemandulan, hal ini akan menurunkan kualitas hidup wanita maupun pria (Prijatni, 2016).

Penurunan penyakit berpotensi wabah merupakan salah satu program yang menjadi fokus di Dinas Kesehatan Kabupaten Lombok Barat. Untuk kasus Demam Berdarah terjadi peningkatan kasus dari 48 kasus Tahun 2014 menjadi 142 kasus Tahun 2015 ini dengan 1 kasus meninggal dunia. Upaya pencegahan penyebaran penyakit berpotensi wabah juga terus dilakukan misalnya dengan komunikasi dan edukasi (KIE), surveilans penyakit. Penanganan kasus sesuai dengan protap juga menjadi hal penting, karena dapat menghambat penyebaran penyakit. Upaya pencegahan penyakit juga dilakukan melalui peningkatan cakupan imunisasi dimana persentase desa yang mencapai "Universal Child Immunization" (UCl) meningkat dari 98,36\% di Tahun 2014 menjadi $100 \%$ pada Tahun 2015. Peningkatan hasil juga diikuti oleh cakupan Imunisasi Dasar Lengkap (IDL) pada bayi dari 94,4\% tahun 2014 menjadi 103,3\% tahun 2015 (Rachman Sahnan Putra, 2015).

Untuk tahun 2015, permasalahan data IMS ini diperoleh data dari laporan LB1, dan ditemukan kasus Syphilis sebanyak 2 kasus dan untuk pemeriksaan kasus IMS dilayani oleh program kesehatan reproduksi. Kasus IMS ini merupakan fenomena gunung es. Hal ini kemungkinan disebabkan oleh keengganan penderita yang mengalami keluhan pada alat reproduksinya untuk memeriksakan diri ke tempat pelayanan publik seperti puskesmas. Oleh sebab itu sangat mendesak untuk segera melakukan pengumpulan data pada klinik/tempat praktek swasta/pribadi. Data yang lengkap akan menjamin penyusunan program yang lebih baik untuk memberantas penyakit tersebut. Hal ini telah ditindaklanjuti oleh seksi Pengamatan Penyakit dimana Tahun 2014 dilakukan pembelajaran dan pelatihan bagi petugas puskesmas dengan wilayah resiko tinggi terhadap IMS ini. Sehingga, diharapkan data dapat diperoleh dengan baik Tahun 2015 terutama di 6 puskesmas yang telah dilatih. Dengan adanya pencatatan tersebut maka intervensi yang dilakukan dapat semakin terarah jelas, meskipun saat ini kenyataannya data yang dapat diperoleh kurang optimal (Rachman Sahnan Putra, 2015).

Permasalahan mengenai kesehatan organ reproduksi sangatlah penting sehingga pemberian promosi kesehatan kepada masyarakat mengenai pentingkan menjaga kesehatan reproduksi dan mengajarkan bagaimana cara membersihkan organ reproduksi yang baik, merupakan langkah yang tepat agar masyarakat sehatdi masa pandemi covid-19 ini. 


\section{METODE}

Kegiatan pendidikan kesehatan dilaksanakan pada hari kamis, 25 Maret 2021 di Aula kampung KB desa Telagawaru, Labuapi Lombok Barat. Mitra kegiatan pengabdian masyarakat adalah Kepala Desa Telagawaru dan memberikan tugas kepada kader kesehatan untuk mendampingi saat pelaksanaan pendidikan kesehatan berlangsung. Peserta yang hadir 10 orang dikarenakan masa pandemi peserta dibatasi dan menyesuaikan dengan luas ruangan aula.

Metode yang digunakan dalam kegiatan ini menggunakan beberapa jenis metode, yaitu: a). Penyuluhan mengenai cara menjaga kebersihan alat kelamin luar wanita, b). Menayangkan video tentang tata cara menjaga kebersihan alat kelamin luar wanita dan c). Latihan cara menjaga kebersihan alat kelamin luar menggunakan model panggul dan alat kelamin luar wanita. Adapun Langkah-langkah pelaksanan kegiatan ini meliputi 3 tahapan yaitu 1). Tahap 1; Pre test, 2). Tahap 2; Materi dan Pelatihan, 3). Tahap 3; Post test

\section{HASIL DAN PEMBAHASAN}

Pelaksanaan kegiatan Pendidikan Kesehatan Reproduksi Pada Masa Pandemi Covid-19 Dan Sosialisasi Pentingnya Peran Orang Tua dalam Memberikan Edukasi Kesehatan Reproduksi Pada Remaja di Desa Telagawaru berjalan dengan lancar. Peserta penyuluhan sangat antusias, dilihat dari kedatangan peserta sebelum acara di mulai, pada saat sesi tanya jawab beberapa peserta menceritakan tentang permasalahan anak remajnya dan perserta lain membantu menjawab pertanyaan peserta yang lain

\section{Tahap 1 : Pre test}

Hasil pre test menunjukkan bahwa pengetahuan warga tentang kesehatan reproduksi dalam kategori kurang yaitu sebesar $70 \%$ warga belum mengetahui cara membersihkan organ reproduksi yang benar. Orang tua merasa tabu untuk menjelaskan tentang kesehatan reproduksi kepada anaknya. Pertanyaan mengenai peran orangtua dalam memberi informasi tentang kesehatan reproduksi ke anaknya juga dalam katagori kurang yaitu $90 \%$ warga menganggap anak nya akan mengetahui tentang kesehatan repoduksi secara alami.

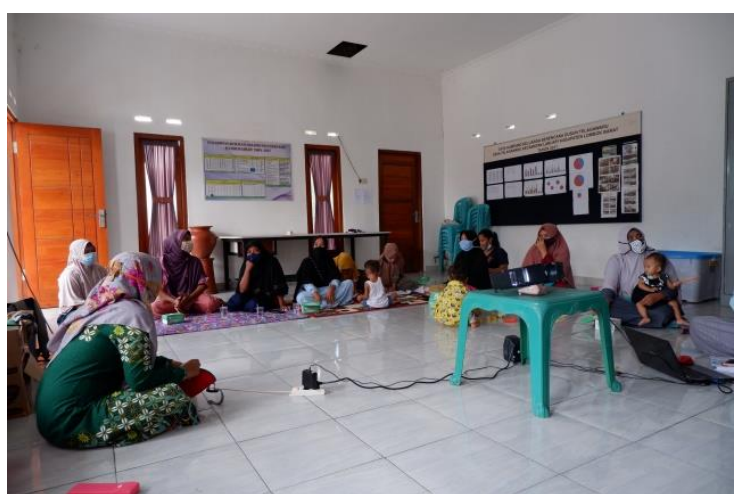

Gambar 1. Pre test

Kurangnya pengetahuan remaja putri dan informasi yang tepat tentang kesehatan organ reproduksi kemungkinan dapat menimbulkan kurangnya perhatian kesehatan organ reproduksinya. Oleh karena itu perlu adanya pemberian informasi yang lengkap pada remaja putri untuk meningkatkan pengetahuan dan kesadaran mereka akan pentingnya menjaga kebersihan diri terutama organ reproduksi termasuk risiko bila tidak dijaga (Departemen Kesehatan Republik Indonesia, 2003)

\section{Tahap 2 : Materi dan pelatihan}

Materi disajikan menggunakan layar LCD, Promosi kesehatan dan penayangan video merupakan cara yang efektif dan lebih baik dalam satu upaya untuk peningkatan derajat kesehatan masyarakat. Latihan atau simulasi juga merupakan salah satu metode untuk menerapkan perilaku sehat yang dianjurkan. Sebagai alternatif pemecahan masalah yang sudah diidentifikasi, maka dilakukan kegiatan peningkatan pengetahuan dan penerapan perilaku kelompok sasaran tentang menjaga kebersihan alat kelamin luar wanita. Metode yang digunakan dalam peningkatan pengetahuan ini adalah dengan memberikan penyuluhan berupa ceramah interaktif dan penayangan videosedangkan untuk penerapan perilaku dilakukan dengan latihan atau simulasi.

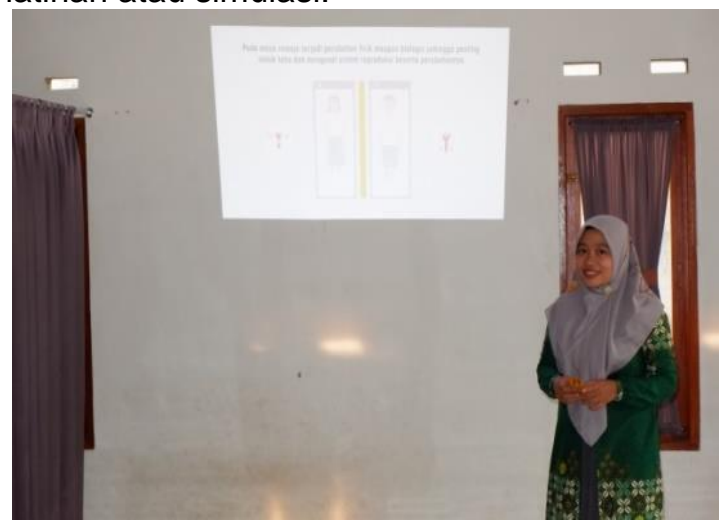

Gambar 2. Pendidikan Kesehatan 
Upaya promosi dan pencegahan masalah kesehatan reproduksi juga perlu diarahkan pada masa remaja, dimana terjadi peralihan dari masa anak menjadi dewasa, dan perubahan-perubahan dari bentuk dan fungsi tubuh terjadi dalam waktu relatif cepat. Hal ini ditandai dengan berkembangnya tanda seks sekunder dan berkembangnya jasmani secara pesat, menyebabkan remaja secara fisik mampu melakukan fungsi proses reproduksi tetapi belum dapat mempertanggung jawabkan akibat dari proses reproduksi tersebut.Informasi dan penyuluhan, konseling dan pelayanan klinis perlu ditingkatkan untuk mengatasi masalah kesehatan reproduksi remaja ini.

Upaya menjaga kebersihan organ genitalia belum banyak diketahui oleh para remaja putri. Salah satu metode untuk menyebarluaskan informasi tentang menjaga kebersihan organ genitalia eksterna adalah melakukan promosi kesehatan. Alternatif metode yang dapat dipergunakan pada promosi kesehatan adalah metode ceramah. Metode ceramah, selain sederhana juga efektif dalam upaya penyampaian informasi secara cepat kepada kelompok sasaran yang cukup besar. Selain itu, untuk mengubah perilaku dapat juga dilakukan dengan simulasi dan atau latihan yang bisa didahului dengan bantuan alat peraga atau video (Notoatmodjo, 2012)

Selain itu lingkungan keluarga dan masyarakat harus ikut peduli dengan kondisi remaja ini sehingga dapat membantu memberikan jalan keluar bila remaja mengalami masalah tidak malah di salahkan, tetapi perlu diarahkan dan dicarikan jalan keluar yang baik dengan mengenalkan tempattempat pelayanan kesehatan reproduksi remaja untuk mendapatkan konseling ataupun pelayanan klinis sehingga remaja masih dapat melanjutkan kehidupanya (Prijatni, 2016)

Seiring dengan peningkatan kasus masalah reproduksi pada remaja sekarang ini, ditambah dengan kondisi pandemi Covid-19 yang dapat menyebabkan kelengahan perempuan dalam kebersihan reproduksi berpotensi menimbulkan masalah kesehatan reproduksi pada perempuan. Tujuan kegiatan pengabdian ini adalah untuk meningkatkan pengetahuan dan berfikir kritis perempuan tentang perubahan fisik remaja di rumah serta untuk meningkatkan pengetahuan remaja putri tentang manajemen kebersihan menstruasi selama masa pandemi Covid-19.

$$
\text { Kegiatan dilaksanakan secara }
$$

langsung dengan menerapkan protokol kesehatan dengan menggunakan metode ceramah. Metode ceramah dipilih untuk memberikan penjelasan tentang manajemen kebersihan organ reproduksi selama pandemi Covid-19 dan pengenalan perubahan fisik remaja selama di rumah.

Metode tanya jawab juga dilaksanakan agar peserta dapat menggali pengetahuan sebanyak-banyaknya tentang materi yang disampaikan. Hasil kegiatan menunjukkan adanya peningkatan pengetahuan, pemahaman, dan kemampuan peserta dalam memahami materi yang disampaikan. Hasil post-test menunjukkan adanya peningkatan persentase sampai $100 \%$ untuk pertanyaan terkait pengetahuan tentang menstruasi yang dikatakan normal apabila terjadi selama di rumah, perubahan fisik yang terjadi.

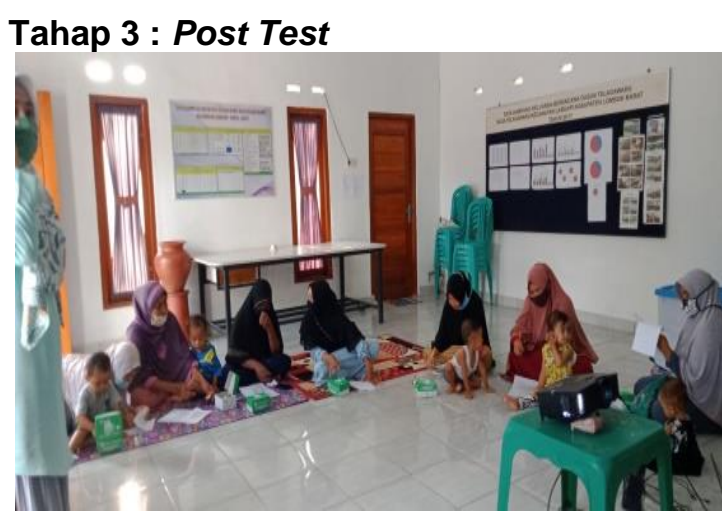

Gambar 3. Kegiatan Post test

Hasil post test menunjukkan bahwa $90 \%$ peserta mengalami peningkatan pengetahuan tentang kesehatan reproduksi. Orang tua sadar bahwa dengan informasi yang benar tentang kesehatan reproduksi maka anak akan terhindar dari perilaku yang tidak baik. Terlebih, jika mereka terpapar dengan dunia internet sehingga mereka bisa mendapat informasi yang belum tentu benar adanya dan justru menyimpang mengenai kesehatan reproduksi. Peran orangtua kemudian menjadi sangat penting untuk pendidikan dini mengenai kesehatan reproduksi yang harus mereka jaga sebelum mencari tau diluar.

\section{SIMPULAN}

Kegiatan pengabdian edukasi kesehatan reproduksi pada masa pandemi covid-19 dan sosialisasi pentingnya peran orang tua dalam memberikan edukasi kesehatan reproduksi pada remaja di desa Telagawaru telah dilaksanakan dan dapat berjalan dengan lancar. Dengan adanya pengabdian ini, lbu-ibu peserta kegiatan pengabdian telah mengetahui tentang cara menjaga kesehatan organ reproduksinya dan telah mengetahui bahwa memberikan informasi kepada anak merupakan hal yang harus dilakukan agar anak tidak mendapatkan informasi yang salah 


\section{UCAPAN TERIMAKASIH}

Penulis mengucapkan terimakasih kepada

1. LPPM UMMAT yang telah memberikan hibah pengabdian kepada masyarakat anggaran 2020-2021

2. Kepada desa telagawaru serta jajarannya

3. Kader kesehatan desa telagawaru

4. Tim pengabdian masyarakat yang solid

\section{DAFTAR RUJUKAN}

Departemen Kesehatan Republik Indonesia. (2003). Kesehatan reproduksi remaja. Jakarta. Depkes RI.

Kementrian Kesehatan Republik Indonesia. (2017). Lampiran Surat Edaran Eliminasi HIV, Sifilis, Hepatitis B.pdf.

Notoatmodjo, S. (2012). Notoatmodjo, S. Promosi Kesehatan Dan Perilaku Kesehatan. Rineka Cipta. Jakarta.

Pemerintah Republik Indonesia. (2014). Peraturan Pemerintah Republik Indonesia Nomor 71 Tahun 2014 Tentang Perlindungan Dan Pengelolaan Ekosistem Gambut. 38. https://peraturan.bpk.go.id/Home/Details/ 5513/pp-no-71-tahun-2014

Prijatni, I. at al. (2016). Kesehatan Reproduksi dan Keluarga Berencana. Kementerian Kesehatan RI, 6.

Rachman Sahnan Putra. (2015). KABUPATEN LOMBOK BARAT TAHUN 2015. 